\title{
The Effects of Water Extracts from Lemon Balm on Colorado Potato Beetle Behaviour
}

\author{
Milena Rusin ${ }^{1 *}$, Janina Gospodarek' \\ 1 Department of Agricultural Environment Protection, University of Agriculture, al. Mickiewicza 21, \\ 31-120 Krakow, Poland \\ * Corresponding author's e-mail: milena_rusin@wp.pl
}

\begin{abstract}
The objective of this study was to determine the effects of various concentrations of water extracts prepared from the fresh or dry mass of lemon balm on the feeding of Colorado potato beetle larvae in L2 and L4 stages. The extracts from the dry matter were prepared at the concentrations of $2 \%, 5 \%$ and $10 \%$ and from the fresh matter at the concentrations of $10 \%, 20 \%$ and $30 \%$. The feeding intensity assessment was conducted by dipping leaves of potato in respective solutions of the extracts and determining the mass of food consumed by larvae, as well as the changes of larvae body weight. In the studies on the olfactory reaction of adult insects, a glass "Y-tube" olfactometer was used. The feeding by L4 larvae of Colorado potato beetle was effectively limited by the extract prepared from the dry matter of lemon balm with $10 \%$ concentration. The larvae at L2 stage turned out to be more susceptible to the effects of extracts - the extracts in almost all used concentrations limited the feeding of the studied pest. The body weight gain in L2 and L4 larvae of Colorado potato beetle were effectively limited by the extracts prepared from the dry plants of lemon balm in as low concentration as $5 \%$. However, the effect of extracts prepared from the fresh matter of lemon balm plants was effective in limiting the body weight gain of L4 larvae at the minimum concentration of $20 \%$, whereas for L4 larvae the effective concentration was $30 \%$. The evident deterrent reaction of odour substances originating from lemon balm plants towards the females of Colorado potato beetle was found. The males did not react to the above-mentioned factor.
\end{abstract}

Keywords: water extracts, Melissa officinalis L., Leptinotarsa decemlineata Say., olfactometer, biological control

\section{INTRODUCTION}

Plant extracts and volatile oils are increasingly often applied in the plant protection measures against pests. These substances have a wide spectrum of action and, moreover, they are safe to the natural environment and easy to prepare. They contain defensive compounds which make difficult or impossible for pests to consume the plants. Therefore, numerous attempts are made to limit the chemical pest control agents via the use of products obtained from herb species [Dankowska and Bendowska 2006, Wawrzyniak 2009, Biniaś and Gospodarek 2017]. The odour of the host plant is a very important factor determining the behaviour and feeding intensity of pests. Therefore, the substances acting as deterrents or preventing the identifi- cation of host plant by pest are used increasingly often [Korczyński and Koźmiński 2007].

Potato (Solanum tuberosum L.) is one of principal cultivated plants in Poland, although in the last decades, a downward trend appeared in both area of cultivation and yields. Nevertheless, it still plays a significant role as a human food source, as well as the animal fodder and a crop rotation species [Kalbarczyk 2004]. Colorado potato beetle (Leptinotarsa decemlineata Say.) is one of the most dangerous pests of potato, causing significant losses in yield. Applying insecticides is one of the main methods of controlling this pest, but adverse effects of using chemicals encourage the search for natural alternatives in the protection of potatoes [Mohammadi et al. 2007, Ebadollahi et al. 2017]. 
Lemon balm (Melissa officinalis L.) is a perennial herb of Lamiaceae family, used in many branches of industry [Badgat and Cosge 2006, Koksal et al. 2011, Saeb et al. 2011, Rostami et al. 2012]. Owing to its allelopathic properties, the water extracts from the plant can be used in protection against weeds [Kato-Noguchi 2001], whereas the volatile oils are used in plant protection against pests [Rafiei-Karahroodi et al. 2011].

The objective of this study was to determine the effects of various concentrations of water extracts prepared from the fresh or dry matter of lemon balm, upon the feeding of Colorado potato beetle larvae in L2 and L4 stages. Furthermore, the reaction of imago forms to the odour of the above herb was studied by means of an olfactometer.

\section{MATERIAL AND METHODS}

The experiment was conducted in a laboratory, in six replicates. Fresh leaves of potato, adults and larvae of Colorado potato beetle used for the analysis at the end of June 2015 were collected.

The extracts from dry matter of Melissa officinalis $\mathrm{L}$. were prepared at the concentration assumed conventionally as $2 \%, 5 \%$ and $10 \%$ (dried plants + cold redistilled water in proportions of $2: 100,5: 100$ and $10: 100)$ and at the concentration of $10 \%, 20 \%$ and $30 \%$ for fresh matter (fresh above-ground parts of plants + cold redistilled water in proportions of $10: 100,20: 100$ and $30: 100)$. The extracts were stored in the dark for the period of 24 hours, and then filtered through filter papers and immediately used for to conduct the experiment. The test was conducted on Petri dishes, and the substrate consisting of moist filter paper. The potato leaves were soaked for $3 \mathrm{sec}-$ onds in adequate plant extracts and in distilled water used as control, and then dried at room temperature. In each dish, a single leaf of potato, suitable for a specific object was placed and then two larvae L2 stage and separately two larvae L4 stage were introduced.

In order to determine the effect of $M$. officinalis extracts on Colorado potato beetle, the mass of food consumed by larvae and larvae weight gain were established once daily. In the studies on the olfactory reaction of the above-mentioned insects, a glass "Y-tube" olfactometer was used. It is commonly used for the evaluation of odour preferences in insects [Vet et al. 1983, Schaller and Nentwig 2000, Ukeh and Umoetok 200, Ran- jith 2007]. "Y- tube" had one inlet tube and two test tubes. The air, cleaned in carbon filter, was forced in by pump and directed to each test tube. Then, the air stream flowed through the source of odour i.e. glass container with either $30 \mathrm{~g}$ of fresh matter of lemon balm together with a wet circle of filter paper (to ensure appropriate air humidity) or only wet filter paper (control). An imago of $L$. decemlineata was placed in the outlet of the inlet tube, and its behaviour observed for 10 minutes, recording the number of incursions into particular test tubes of the olfactometer (with or without the odor derived from lemon balm). The experiment with pest insects was performed in 12 repetitions, separately for males and females.

The obtained results were subjected to analysis with STATISTICA 10.0 software. The significance of differences between the means were tested by univariate analysis of variance, and the means were differentiated by Fisher's LSD test at $\alpha=0.05$. The $t$-test for independent samples was used with respect to the results obtained using the olfactometer (the grouping variable was the presence or absence of the odor of tested plant).

\section{RESULTS AND DISCUSSION}

The extract from dry matter at $10 \%$ concentration adversely affected the feeding of L4 larvae of Colorado potato beetle, and at all dates of observations the mass of food eaten by larvae on this object was significantly lower than in control (Table 1). Furthermore, $72 \mathrm{hrs}$ after the inception of the experiment, a significant effect of feeding hampering was noted for 5\% dry matter concentration, and 30\% fresh matter concentration. In line with the increase in the concentrations of the extracts from fresh and dry matter, their adverse effect increased also with respect to L4 larvae of Colorado potato beetle.

The L2 larvae of Colorado potato beetle were much more susceptible on the effect of lemon balm extracts. Almost all applied extracts, both those prepared from the fresh and dry matter, significantly limited the feeding of the studied pest (except the extract from dry matter at $2 \%$ concentration). The most disadvantageous effect was noted in the case of the extract prepared from fresh matter with $30 \%$ concentration, where - after the observation - the mass of food eaten by L 2 larvae was $60 \mathrm{mg}$ lesser than that in the control experiment. 
Table 1. The effect of extracts from Melissa officinalis L. on the food mass eaten by the larvae of Leptinotarsa decemlineata Say. [mg]

\begin{tabular}{|c|c|c|c|c|}
\hline Object & $12 \mathrm{~h}$ & $24 \mathrm{~h}$ & $48 \mathrm{~h}$ & $72 \mathrm{~h}$ \\
\hline \multicolumn{5}{|c|}{ Larvae L4 } \\
\hline$C$ & $38.67 b^{*}$ & $87.00 \mathrm{~b}$ & $157.17 \mathrm{~b}$ & $251.67 \mathrm{c}$ \\
\hline DM 2\% & $34.33 \mathrm{~b}$ & $84.00 \mathrm{~b}$ & $160.17 b$ & $224.00 \mathrm{bc}$ \\
\hline DM 5\% & $15.00 \mathrm{ab}$ & $33.17 \mathrm{ab}$ & $94.00 \mathrm{ab}$ & $130.00 \mathrm{a}$ \\
\hline DM $10 \%$ & $12.17 \mathrm{a}$ & $32.67 \mathrm{a}$ & $78.33 \mathrm{a}$ & $121.50 \mathrm{a}$ \\
\hline FM 10\% & $31.50 \mathrm{~b}$ & $64.83 \mathrm{ab}$ & $143.50 \mathrm{ab}$ & 221.83 bc \\
\hline ŚW 20\% & $27.33 \mathrm{ab}$ & $52.50 \mathrm{ab}$ & $111.83 \mathrm{ab}$ & $179.83 \mathrm{abc}$ \\
\hline FM 30\% & $21.67 \mathrm{ab}$ & $43.17 \mathrm{ab}$ & $98.83 a b$ & $157.33 \mathrm{ab}$ \\
\hline \multicolumn{5}{|c|}{ Larvae L2 } \\
\hline C & $28.67 b$ & $51.17 \mathrm{~b}$ & $99.0 \mathrm{~d}$ & $145.00 \mathrm{c}$ \\
\hline DM 2\% & $26.33 \mathrm{ab}$ & $50.33 \mathrm{~b}$ & $83.33 \mathrm{c}$ & $127.17 b$ \\
\hline DM 5\% & $16.17 \mathrm{a}$ & $35.67 \mathrm{a}$ & $69.50 \mathrm{ab}$ & $84.17 \mathrm{a}$ \\
\hline DM $10 \%$ & $14.50 \mathrm{a}$ & $33.83 \mathrm{a}$ & $62.17 \mathrm{a}$ & $89.00 \mathrm{a}$ \\
\hline FM 10\% & $12.50 \mathrm{a}$ & $27.33 \mathrm{a}$ & $70.17 \mathrm{~b}$ & $126.33 \mathrm{~b}$ \\
\hline ŚW 20\% & $13.83 \mathrm{a}$ & $32.83 \mathrm{a}$ & $79.00 \mathrm{bc}$ & $130.83 \mathrm{~b}$ \\
\hline FM 30\% & $13.17 \mathrm{a}$ & $27.17 \mathrm{a}$ & $54.00 \mathrm{a}$ & $82.83 a$ \\
\hline
\end{tabular}

Symbols: C - control, DM - dry matter, FM - fresh matter.

* Values for individual terms of observations marked by different letters are statistically different $(\alpha=0.05)$.

The Colorado beetle larvae at L4 stage, feeding in the objects employing the extracts from fresh and dry matter at two highest concentrations, showed, as early as after $24 \mathrm{hrs}$ from the inception of experiment, significantly lower body weight gain than the larvae feeding in the control experiment (Table 2). The extracts prepared from dry matter at $2 \%$ concentration, and from the fresh matter at $10 \%$ concentration, proved to be ineffective in limiting the body weight gain in L4 larvae. The extracts prepared from dry matter at $5 \%$ and $10 \%$ concentrations, as well as those prepared from the fresh matter at $30 \%$ concentration, limited the body weight gain in L2 larvae of Colorado potato beetle. However, it was noted that $72 \mathrm{hrs}$ after the inception of experiment, all the applied extracts, both these prepared from the fresh and dry matter of lemon balm ,had contributed to the decreases in the body weight gain in the L2 larvae of the studied pest.

Few studies on the effects of water extracts from lemon balm upon the feeding of Colorado potato beetle and other pest of cultivated plants have been performed to date. Only Hiiesaar et al. [2000] demonstrated that the water extract of this plant resulted in more than fifteen-fold lower number of eggs laid by the females of Trialeurodes vaporariorum, and - owing to that - it can be potentially used to protect glasshouse plants against this pest. Our earlier studies showed that the extracts obtained from other herb plants could effectively limit the feeding by Colorado potato beetles. The extracts prepared from dry matter of wormwood (Artemisia absinthium L.) at $10 \%$ concentration, and from fresh matter with $30 \%$ concentration result in more than threefold decrease in the amount of food eaten by L2 larvae of Colorado potato beetle, and limit their body weight gain [Rusin et al. 2015]. In the presented experiment, the effect of lemon balm was stronger; even lower concentrations of the applied extracts limited the feeding of the studied pests. In the study by Biniaś et al. [2016 b], all applied extracts prepared from the dry and fresh matter of sage (Salvia officinalis L.) contributed to the decreases in mass of food eaten by L4 larvae. In our experiment, such an effect was noted only in the case of the highest concentration of the extract from dry matter of lemon balm. Furthermore, the limiting effect on the feeding by Colorado potato beetles were noted in the cases of water extracts from St. John's wort (Hypericum perforatum L.) [Biniaś et al. 2016 a], tarragon (Artemisia dracunculus L.) [Rusin et al. 2016 a], and wild thyme (Thymus serpyllum L.) [Rusin et al. $2016 \mathrm{c}$ ].

Many authors emphasise the fact that olfactory stimuli can play a significant role in limiting the feeding activities of pests [Koschier et al. 2002, Koschier and Sedy 2003, Katerinopoulos et al. 2005]. In our experiment, an evident nega- 
Table 2. The effect of extracts from Melissa officinalis L. on larvae body weight gain [mg]

\begin{tabular}{|c|c|c|c|c|}
\hline Object & $12 \mathrm{~h}$ & $24 \mathrm{~h}$ & $48 \mathrm{~h}$ & $72 \mathrm{~h}$ \\
\hline \multicolumn{5}{|c|}{ Larvae L4 } \\
\hline C & $7.3 a^{*}$ & $32.1 \mathrm{c}$ & $34.5 \mathrm{c}$ & $37.2 \mathrm{c}$ \\
\hline DM 2\% & $7.1 \mathrm{a}$ & $29.8 \mathrm{c}$ & $31.6 \mathrm{c}$ & $32.7 \mathrm{bc}$ \\
\hline DM 5\% & $4.2 \mathrm{a}$ & $5.4 \mathrm{a}$ & $6.2 \mathrm{a}$ & 8.9 a \\
\hline DM $10 \%$ & $3.8 \mathrm{a}$ & $4.9 a$ & $4.9 a$ & $5.1 \mathrm{a}$ \\
\hline FM 10\% & $6.4 \mathrm{a}$ & $25.7 \mathrm{bc}$ & $28.9 \mathrm{bc}$ & $31.8 \mathrm{bc}$ \\
\hline ŚW 20\% & $6.1 \mathrm{a}$ & $18.6 \mathrm{~b}$ & $22.1 \mathrm{~b}$ & $25.3 \mathrm{~b}$ \\
\hline FM 30\% & $5.3 a$ & $8.7 \mathrm{a}$ & $10.8 \mathrm{a}$ & $15.8 \mathrm{ab}$ \\
\hline \multicolumn{5}{|c|}{ Larvae L2 } \\
\hline $\mathrm{C}$ & $6.2 \mathrm{~b}$ & $8.8 \mathrm{~b}$ & $13.4 \mathrm{~b}$ & $18.6 \mathrm{c}$ \\
\hline DM $2 \%$ & $5.4 \mathrm{ab}$ & $6.9 a b$ & $11.2 \mathrm{~b}$ & $13.7 \mathrm{bc}$ \\
\hline DM 5\% & $1.6 \mathrm{a}$ & $2.8 \mathrm{a}$ & $4.2 \mathrm{a}$ & $4.6 \mathrm{a}$ \\
\hline DM $10 \%$ & $1.0 \mathrm{a}$ & $1.3 a$ & $1.4 \mathrm{a}$ & $1.8 \mathrm{a}$ \\
\hline FM 10\% & $4.8 \mathrm{ab}$ & $6.1 \mathrm{ab}$ & $9.5 \mathrm{~b}$ & $11.9 \mathrm{~b}$ \\
\hline ŚW 20\% & $4.3 \mathrm{ab}$ & $5.8 \mathrm{a}$ & $9.1 \mathrm{~b}$ & $10.5 \mathrm{~b}$ \\
\hline FM 30\% & $1.2 \mathrm{a}$ & $1.4 \mathrm{a}$ & $1.8 \mathrm{a}$ & $2.1 \mathrm{a}$ \\
\hline
\end{tabular}

Symbols as in Table 1.

* Values for individual terms of observations marked by different letters are statistically different $(\alpha=0.05)$

Table 3. Responses of pests to the odors derived from Melissa officinalis L. fresh matter expressed as a number of entrance per one insect into selected areas of Y-tube olfactometer

\begin{tabular}{|c|c|c|}
\hline Pest & Control & Melissa officinalis L. \\
\hline Leptinotarsa decemlineata Say. - females* & 0.87 & 0.37 \\
\hline Leptinotarsa decemlineata Say. - males & 0.63 & 0.37 \\
\hline
\end{tabular}

* Differences significant at $\alpha=0.05$, in other cases differences were not proven statistically.

tive reaction to the odour substances originating from the fresh matter of lemon balm was noted among the females of Colorado potato beetle $(\mathrm{t}=2.26, \mathrm{P}=0.041)$ (Table 3). The control tube was selected by the pest almost three times as often than the tube of the olfactometer where the odour of lemon balm was introduced. The males of $L$. decemlineata also visited the the control tube more often than that where the odour of lemon balm was pumped; however, in this case, the differences had not been proven statistically $(\mathrm{t}=0.97, \mathrm{P}=0.350)$. The data pertaining to the effect of odour substances originating from nonhost plants upon the behaviour of adult individuals of $L$. decemlineata are diverse. In their study, Rusin et al. [2016 b] demonstrated the strong deterrent reaction of odour substances originating from $A$. absinthium towards the males of Colorado potato beetle. In the study by Biniaś et al. [2016 a, 2016 b], however, no evident deterrent effect of odour substances originating from $S$. officinalis and $H$. perforatum $\mathrm{L}$. towards the adult individuals of Colorado potato beetle was found.

\section{CONCLUSIONS}

1. The feeding by L4 larvae of Colorado potato beetle was effectively limited by the extract prepared from dry matter of lemon balm at $10 \%$ concentration. The larvae at L2 stage turned out to be more susceptible to the effects of extracts - the extracts in almost all used concentrations limited the feeding by the studied pest.

2. The body weight gain in L2 and L4 larvae of Colorado potato beetle were effectively limited by the extracts prepared from the dry plants of lemon balm in as low concentration as $5 \%$. However, the effect of the extracts prepared from the fresh matter of lemon balm plants was effective in limiting the body weight gain of L4 larvae at the minimum concentration of $20 \%$, whereas for L2 larvae the effective concentration was $30 \%$.

3 . The evident deterrent reaction of odour substances originating from lemon balm plants towards the females of Colorado potato bee- 
tle was found, which suggests the possibility of using that plant as a neighbouring crop in mixed cultivation or as e.g. as a component of edge strips. The males of $L$. decemlineata did not react to the above-mentioned factor.

\section{Acknowledgments}

Scientific publication financed by the Ministry of Science and Higher Education of the Republic of Poland

\section{REFERENCES}

1. Azad M.A.K, Yesmin M.N., Islam M.S. 2012. Effect of botanical extract on pest control in brinjal field. J. Environ. Sci. \& Natural Resources, 5(2), 173-176.

2. Bagdat R.B., Cosge B. 2006. The essential oil of lemon balm (Melissa officinalis L.), its components and using fields. J. Fac. Agric. OMU, 21(1), 116-121.

3. Biniaś B., Gospodarek J., Rusin M. 2016 a. Effect of aqueous extract of St. John's Wort (Hypericum perforatum L.) on the Colorado potato beetle (Leptinotarsa decemlineata Say) behaviour. J. Res. Appl. Agric. Eng., 61(4), 25-29.

4. Biniaś B., Gospodarek J., Rusin M. 2016 b. The effect of extracts from sage (Salvia officinalis L.) on black bean aphid (Aphis fabae Scop.) and Colorado potato beetle (Leptinotarsa decemlineata Say.) behaviour. Zesz. Probl. Post. Nauk Rol., 586, 135-145 (in Polish).

5. Biniaś B., Gospodarek J. 2017. Effect of water extract from chamomile on black bean aphid and colorado potato beetle. J. Ecol. Eng., 18(3), 118-124.

6. Dankowska E., Bendowska, J. 2006. Further studies on the effect of plant infusions on the feeding of Deroceras leave (O. F. Müller, 1774). Folia Malacol., 14, 57-60.

7. Ebadollahi A., Geranmayeh J., Kamrani M. 2017. Colorado potato beetle (Leptinotarsa decemlineata Say) control potential of essential oil isolated from iranian Cymbopogon citratus Stapf. Nat. Prod. Sci., 23(4), 235-238.

8. Hiiesaar K., Metspalu L., Kuusik A. 2000. Insectplant chemical interaction: the behavioural effects evoked by plant substances on greenhouse pests. Transactions of the Estonian Agricultural University, 209, 46-49.

9. Kalbarczyk R. 2004. The relation between agrometeorological factors and the potato crop yields in different regions of Poland. Acta Agrophysica, 4(2), 339-350 (in Polish).
10. Kato-Noguchi H. 2001. Effects of lemon balm (Melissa officinalis L.) extract on germination and seedling growth of six plants. Acta Physiol. Plant., 23(1), 49-53.

11. Katerinopoulos H.E., Pagona G., Afratis A., Stratigakis N., Roditakis N. 2005. Composition and insect attracting activity of the essential oil of Rosmarinus officinalis. J. Chem. Ecol., 31, 111-122.

12. Korczyński I., Koźmiński R. 2007. Response of large pine weevil Hylobius abietis (L.) (Coleoptera, Curculionidae) beetles to the smell of alcoholic extract from plants of selected species. Acta Sci. Pol., 6(1), 27-31.

13. Koschier E.H., Sendy K.A. 2003. Labiate essential oils affecting host selection and acceptance of Thrips tabaci Lindeman. Crop. Prot., 22(7), 929-934.

14. Koschier E.H., Sendy K.A., Novak J. 2002. Influence of plant volatiles on feeding damage caused by the onion thrips Thrips tabaci Lindeman. Crop Prot., 22(7), 929-934.

15. Koksal E., Bursal E., Dikici E., Tozoglu F., Gulcin I. 2011. Antioxidant activity of Melissa officinalis leaves. J. Med. Plant. Res., 5(2), 217-222.

16. Mohammadi S.M., Hejazi M.J., Mohammadi A., Rashidi M.R. 2007. Resistance status of the Colorado potato beetle, Leptinotarsa decemlineata, to endosulfan in East Azarbaijan and Ardabil provinces of Iran. J. Insect. Sci., 7, 1-7.

17. Rafiei-Karahroodi Z., Moharramipour S., Farazmand H., Karimzadeh-Esfahani J. 2011. Insecticidal effect of six native medicinal plants essential oil on Indian meal moth, Plodia Interpunctella Hübner (Lep.: Pyralidae). Mun. Ent. Zool., 6(1), 339-345.

18. Ranjith A.M. 2007. An inexpensive olfactometer and wind tunnel for Trichogramma chilonis Ishii (Irichogrammatidae:Hymenoptera). J. Trop. Agri., 45(1-2), 63-65.

19. Rostami H., Kazemi M., Shafiei S. 2012. Antibacterial activity of Lavandula officinalis and Melissa officinalis against some human pathogenic bacteria. Asian J. Biochem., 7(3), 133-142.

20. Rusin M., Gospodarek J., Biniaś B. 2015. The effect of water extracts from Artemisia absinthium L. on feeding of Leptinotarsa decemlineata Say. larvae. J. Res. Appl. Agric. Eng., 60(4), 80-83.

21. Rusin M., Gospodarek J., Biniaś B. 2016 a. Effect of aqueous extracts from tarragon (Artemisia dracunculus L.) on feeding of selected crop pests. Res. Appl. Agric. Eng., 61(4), 143-146.

22. Rusin M., Gospodarek J., Biniaś B. 2016 b. Effect of water extracts from Artemisia absinthium L. on feeding of selected pests and their response to the odor of this plant. JCEA, 17(1), 188-206. 
23. Rusin M., Gospodarek J., Biniaś B. 2016 c. The effect of water extract from wild thyme on Colorado potato beetle feeding. J. Ecol. Eng., 17(4), 197-202.

24. Saeb K., Gholamrezaee S., Asadi M. 2011. Variation of antioxidant activity of Melissa officinalis leaves extracts during the different stages of plant growth. Biomed. Pharmacol. J., 4(2), 237-243.

25. Schaller M., Nentwig W. 2000. Olfactory orientation of the seven-spot ladybird beetle, Coccinella septempunctata (Coleoptera: Coccinellidae): Attraction of adults to plants and conspecific females.
Eur. J. Entomol. 97, 155-159.

26. Ukeh D.A., Umoetok S.B.A. 2007. Effects of host and non-host plant volatiles on the behavior of the Lesser Grain Borer, Rhyzopertha dominica (Fab.). J. Entomol., 4(6), 435-443.

27. Vet L.E.M., Van Lenteren J.C., Meelis E. 1983. An airflow olfactometer for measuring olfactory responses of hymenopterous parasitoids and other small insects. Physiol. Entomol., 8, 97-106.

28. Wawrzyniak M. 2009. Effect of extracts from Geraniaceae plants on Pieris brassicae L. JCEA, 10(4), 361-365. 